\title{
Work experience at height suppressed the effect of dynamic visual input on postural sway when static visual cues were visible
}

\author{
STEVEN R. TORGERUD' | HYEYOUNG CHO² | JAMES D. MCGLOTHLIN | SHIRLEY RIETDYK²
}

1Division of Life Sciences and Foundations, Palmer College of Chiropractic, IA, USA.

2Department of Health and Kinesiology, Purdue University, IN, USA.

${ }^{3}$ School of Health Sciences, Purdue University, IN, USA.

Correspondence to: S. Rietdyk, Department of Health and Kinesiology, Lambert Fieldhouse, 800 West Stadium Ave, Purdue University, West Lafayette, IN 47907-2046.

\section{HIGHLIGHTS}

- Workers with two or more years of roofing experience were compared to controls.

- Roofers used stationary cues to reduce sway when in a moving room.

- Controls did not reduce sway with stationary cues.

- Reduced sway with stationary cues observed in both young and middle-aged roofers.

- Roofers appear to weight stationary visual cues more than controls.

$\begin{array}{ll}\text { ABBREVIATIONS } \\ \text { AP } & \text { anterior-posterior } \\ \text { APRMS } & \text { anterior-posterior root mean } \\ & \text { square } \\ \text { COP } & \text { center of pressure }\end{array}$

PUBLICATION DATA

Received 20 Dec 2018

Accepted 16 Feb 2019

Published 01 May 2019
BACKGROUND: Balance skills are challenged at the roofing worksite by dynamic visual cues in the form of clouds and trees that move with the wind; any instability may result in a fall from height.

AIM: To determine if roofers are less susceptible to a dynamic visual surround (moving room) when stationary cues were available, relative to people who do not work in a similar environment.

METHOD: Forty male adults participated, including young roofers ( $\mathrm{N}=10,26.3$ years), middle-aged roofers $(\mathrm{N}=10$, 50.6 years), young controls ( $N=10,26.2$ years) and middle-aged controls ( $N=10,55.1$ years). Center of pressure root mean square (APRMS) was assessed during quiet standing and four moving room conditions when stationary cues were: (1) not in place, (2) in the foreground (inside the moving room), (3) in the background (outside the moving room, but still visible) and (4) in the foreground and background.

RESULTS: A work group by visual cue interaction was observed $(p=0.032)$, where roofers had up to $18 \%$ lower APRMS relative to controls when the background references were in place. The interaction effect was independent of age.

CONCLUSION: The roofers were able to suppress visually-induced postural sway when stationary visual cues were present in the background, likely due to the severe consequences for loss of balance when working at height. The suppression was maintained in aging workers.

KEYWORDS: stability | vision | moving room | balance | sensory weighting

\section{INTRODUCTION}

While standing, postural sway information is obtained from the visual, vestibular, and somatosensory inputs. ${ }^{1}$ These inputs can be manipulated with moving rooms, galvanic stimulation, and tendon vibration, among other protocols, in order to understand the contribution of each sensory system. The weighting of the sensory stimuli from each system can be increased or decreased, dependent on the accuracy and reliability of that stimulus (e.g. Johansson et al., 1995) ${ }^{2}$. Furthermore, relative weightings of sensory stimuli vary as a function of the environmental conditions. ${ }^{3}$ Prolonged exposure to galvanic stimulation ${ }^{2,4}$ and vibratory proprioceptive stimulation ${ }^{4-8}$ resulted in progressive reduction in body sway and change in body leaning over time. This observation suggests there is decreased weighting on the inaccurate sensory system - vestibular in the former case and muscle spindles in the latter. Support for decreased weighting on visual information with prolonged exposure to a

\begin{tabular}{l|l|l|l|l}
\hline Torgerud et al. & 2019 & VOL.13 & N.1 & https://doi.org/10.20338/bjmb.v13i1.122
\end{tabular}


moving visual scene has also been reported.9,10 During exposure to a moving visual scene, subjects adapted to the conflicting sensory information by decreasing the sway energy at the stimulus frequency, consistent with the concept of suppression of the visual stimulus, or decreased visual weighting. In the preceding studies, participants decreased sway within one minute of exposure to the moving visual scene. Since laboratory-based studies have demonstrated an acute adaptation to conflicting sensory information, it is reasonable to expect that chronic exposure (years) to specific environmental conditions may lead to a general suppression of a sensory stimulus. When a person is exposed daily to moving visual cues through their work demands, the parallel expectation is that they will be less susceptible to moving visual cues.

Workers who repair residential roofs (commonly termed "roofers") work in a challenging environment which includes varying roof pitch angles, varying frictional surfaces, wind gusts, carrying heavy loads, and an environment cluttered with tools, electrical cords and loose shingles. These challenges may be compounded by the unique visual environment. While the roof provides a stable visual cue in the lower visual field, other structures in the upper visual field - such as other workers, tree tops, and clouds - are subject to movement. This is different from people on the ground, with fences, buildings, tree trunks, lamp posts, etc. providing stable visual cues in the lower and upper visual fields. It is well known that dynamic visual disturbances lead to increased postural displacement, ${ }^{9,10}$ and it is possible that moving cues in the upper visual field of the roofer will increase postural sway. Although a stable lower visual field is available, the whole visual field does not have to be moving in order to observe increased postural sway. ${ }^{11}$ If the perturbation due to working on a slope, for example, is compounded by small deviations in center of mass displacement due to dynamic visual disturbances, the result could be a fall from height. Faced with this environment and the dire consequences, roofers may suppress dynamic visual input in order to stabilize their balance. However, roofers may not simply suppress the dynamic visual input; they may also be more likely to use stationary visual cues for reducing postural sway. When stationary cues are available, they provide visual structure that may be helpful in improving motor performance ${ }^{12,13}$. For example, visual references at the worksite have been recommended as they reduced center of pressure (COP) displacement at height and on slopes in a static lab environment. ${ }^{14,15}$ However, perception studies conducted in a visually dynamic environment demonstrate that the perceptual illusion of self-motion (vection) increased with a stable visual reference in the foreground, and vection decreased with a stable reference in the background. ${ }^{16-18}$ Increased vection with foreground references was attributed to the introduction of a relative-motion signal into what would have been an absolute-motion signal. ${ }^{13}$ There is evidence that perceptions of vection are related to postural change,$^{19}$ so it reasonable to expect that stationary foreground cues would increase postural movement, while stationary background cues would decrease postural movements.

The workforce is aging, and increases in work-related fall injuries have been observed in each decade between 25 and 65 years of age. ${ }^{20}$ With advancing age, balance and stability are compromised by progressive declines in neuromuscular, skeletal, and cognitive systems. ${ }^{21}$ This is especially important for the aging worker who has not yet reached retirement age and also works at a balance-challenging worksite. In studies that did not examine a particular occupation, middle-aged adults (typically defined as ages 40-65 years) did not show gait differences relative to young adults (such as walking on level ground

\begin{tabular}{l|l|l|l|l}
\hline Torgerud et al. & 2019 & VOL.13 & N.1 &
\end{tabular}

https://doi.org/10.20338/bjmb.v13i1.122 
Brazilian Journal of Motor Behavior

at natural cadences).22,23 However, more challenging tasks, such as walking faster or stepping over obstacles, revealed differences in middle age that were more similar to gait behavior of older adults (typically defined as older than 60 or 65 years). ${ }^{24,25}$ Thus, the inherent challenges of the roofing worksite may be especially problematic for the aging roofer. In response to a dynamic visual stimulus, older adults sway more. ${ }^{11,26}$ Increased sway associated with aging may increase probability of a fall. Conversely, there may be some benefit to daily exposure to challenging tasks, as outlined in the following observations. First, balance skills are maintained by challenging the balance of the older adults through exercise interventions. ${ }^{27}$ Second, extensive exposure to various work tasks and environments are related to performance. ${ }^{28}$ Third, job-specific tasks maintained physical capacity in older power line technicians. ${ }^{29}$ Fourth, increased physical demand of the job was associated with better functional balance. ${ }^{30}$ Finally, work experience mitigated age-related differences in balance and mobility. ${ }^{31}$ These observations support the idea that daily exposure to a high fall-risk worksite may alleviate increased fall-risk associated with age. Therefore, it is reasonable to expect that the ability to suppress dynamic visual information will be maintained in those roofers who continue working on the roof as they age.

The purposes of this research were (1) to determine how work experience in visually challenging environments affected susceptibility to the destabilizing effects of a dynamic visual environment, and (2) to determine if any decreases in susceptibility were maintained in middle-aged roofers. Four groups were examined: young roofers, young non-roofers (hereafter called controls), middle-aged roofers, and middle-aged controls (young participants were between the ages of 20-35 years and middle-aged participants were between the ages of 45-60 years). A moving room was used to provide dynamic visual input while standing still. Stationary visual cues ( $2 \mathrm{~m}$ tall poles) were either not present, placed inside the moving room (foreground cues), placed outside the moving room (background cues), or placed in the foreground and background. The dependent variable is anteriorposterior root mean square (APRMS) of the COP displacement. We hypothesized that roofers would demonstrate lower APRMS in the moving room when compared to controls. We also hypothesized that roofers would demonstrate lower APRMS when stationary cues were available in the background and/or foreground compared to controls. Finally, we hypothesized that the ability to use these stationary cues would not be affected by age (no interactions with age would be observed).

\section{METHODS}

\section{Subjects}

Forty-one healthy males participated with informed consent; subjects received an honorarium for participating. Experimental procedures were approved by the Purdue University Institutional Review Board, and all subjects signed informed consent. One subject was excluded due to an exaggerated response to the stimulusi, as observed visually during data collection and by the largest COP RMS (109\% larger than the average and outside the mean plus two standard deviations). Four groups were examined: Younger roofers, middleaged roofers, younger controls and middle-aged controls. 
The large response to the moving room may be due to the subject's navy experience. Inside a moving ship, conflicting sensory information is perceived: vestibular information indicates self-movement, while the stationary visual field indicates no self-movement. Therefore, sailors may have higher visual weightings, making them more susceptible to the moving room stimulus.

Age range for the younger groups was 20 to 35 years; for the middle-aged groups, 45 to 60 years (Table 1). Inclusion criteria for the roofers included current employment in the roofing industry, currently working at height, and a minimum of two years experience as a roofer. Exclusion criteria included any known neurological, vestibular or orthopaedic disorders that would affect balance. Vision was normal or corrected-to-normal for all subjects. The professions of the younger controls were nine students (seven graduate and two undergraduate) and one semi-truck driver. The middle-aged controls consisted of three professors, one graduate student, one academic advisor, one sales representative, one environmental scientist, one manager, one office worker, and one clergyman. Females were not excluded from the study; however, no female roofers volunteered for the study. The control group was matched for sex and age; therefore, the control group was also male. The four groups were not different in height (Table 1). No interaction of age by work was observed for body mass, but main effects were observed for age $(F(1,36)=7.06, p=0.01)$ and work $(F(1,36)=4.62, p=0.04)$. Higher body mass was observed in the middle-aged groups relative to young groups, and in the control groups relative to roofer groups (Table 1).

Table 1 - Demographic information of the participants; mean with standard deviation in parentheses.

\begin{tabular}{lcccccc} 
& Younger Controls & $\begin{array}{c}\text { Middle-aged } \\
\text { Controls }\end{array}$ & \multicolumn{2}{c}{ Younger Roofers } & \multicolumn{2}{c}{$\begin{array}{c}\text { Middle-aged } \\
\text { Roofers }\end{array}$} \\
\hline $\mathrm{N}$ & 10 & \multicolumn{1}{c}{10} & & 10 & & 10 \\
$\mathrm{Age}($ years $) \dagger$ & $26.2(3.7)$ & $55.1(4.5)$ & 26.3 & $(3.1)$ & 50.6 & $(4.2)$ \\
Height $(\mathrm{cm})$ & $179.5(5.5)$ & $179.4(7.5)$ & 175.4 & $(17.9)$ & 176.0 & $(8.0)$ \\
Mass $(\mathrm{kg}) \dagger \ddagger$ & $80.7(15.3)$ & $97.3(22.7)$ & 74.5 & $(6.8)$ & 83.7 & $(10.2)$ \\
Years roofing $\dagger$ & $\mathrm{n} / \mathrm{a}$ & $\mathrm{n} / \mathrm{a}$ & 6.3 & $(4.6)$ & 17.6 & $(9.1)$ \\
\hline
\end{tabular}

$\dagger$ indicates an age effect $(p \leq 0.05)$

$\ddagger$ indicates a work effect $(p \leq 0.05)$

No interactions of work by age were observed.

\section{Experimental Setup}

Ground reaction forces were recorded with a forceplate (AMTI, Watertown, MA) at $240 \mathrm{~Hz}$. One infra-red emitting diode was placed on the moving surround, collected at $60 \mathrm{~Hz}$ (Optotrak, Northern Digital, Inc.). The ground reaction forces were synchronized with the Optotrak coordinate data. The visual surround $(1.2 \mathrm{~m}$ wide by $1.2 \mathrm{~m}$ deep by $2.3 \mathrm{~m}$ tall, Figure 1) was driven by a motor to produce a sinusoidal anterior-posterior (AP) translation $(13 \mathrm{~cm}$ peak-to-peak displacement at $0.24 \mathrm{~Hz}$ ). A slanted panel $(1.2 \mathrm{~m}$ wide by $56 \mathrm{~cm}$ deep, figure 1b) was attached to the bottom of the front vertical panel to obstruct view of the laboratory floor unless the subject fully flexed his/her neck. The top half of the front wall was transparent. Black circles (2 to $12 \mathrm{~cm}$ diameter range) were arranged in a random pattern on the walls, with about 15 circles per square meter. Two 36 inch, 30 -Watt fluorescent lights were mounted on the top of the side walls inside the surround, and two 1000 Watt spotlights were mounted above and in front of the surround and pointed at the ceiling (Figure 1a). A

\begin{tabular}{l|l|l|l|l}
\hline Torgerud et al. & 2019 & VOL.13 & N.1 \\
\hline
\end{tabular}


monochromatic background was created with a white canvas sheet suspended in front of the surround (Figure 1a). Stationary references were constructed of PVC pipe $(6 \mathrm{~cm}$ diameter, $2 \mathrm{~m}$ height) which were painted black (Figure 1d). Foreground stationary references were positioned in the peripheral field of view $(50 \mathrm{~cm}$ in front of the subject at a 45 degree angle from the midpoint between the ankles). ${ }^{16}$ Background references were placed $0.4 \mathrm{~m}$ apart, $50 \mathrm{~cm}$ beyond the position of the surround (Figure 1a). ${ }^{16} \mathrm{~A}$ translucent plastic sheet was draped over the transparent portion of the front wall when the background references were not in place to prevent the canvas backdrop from functioning as a stable visual background.

\section{Experimental Conditions and Design}

The study was a mixed between- and within-subjects design. Between-subject variables included age and work experience, and the within-subject variable was visual stimuli. Five visual stimuli conditions included: (1) quiet standing (visual surround not in place), (2) moving visual surround with no stationary references (Figure 1b), (3) moving visual surround with background references (Figure 1c), (4) moving visual surround with foreground references (Figure 1d) and (5) moving visual surround with foreground and background references (Figure 1e).
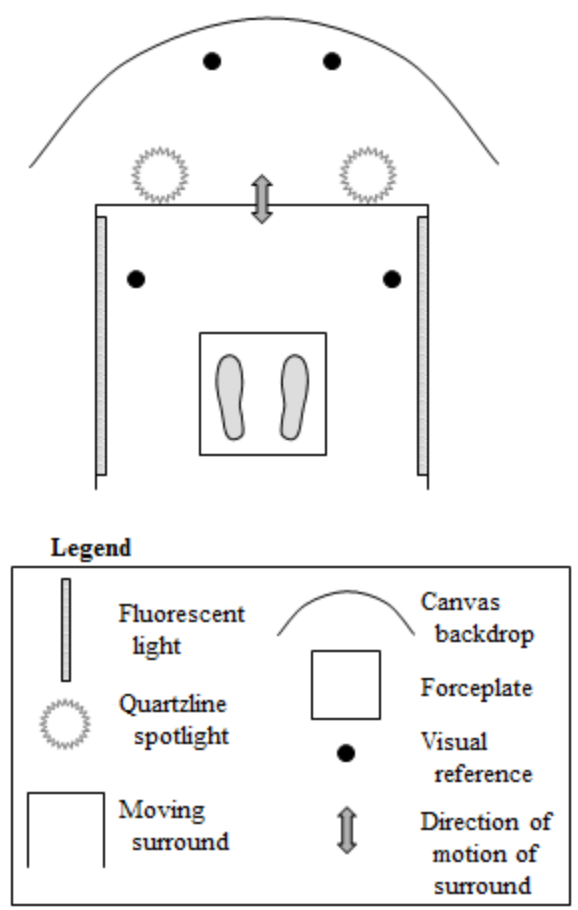

(a)

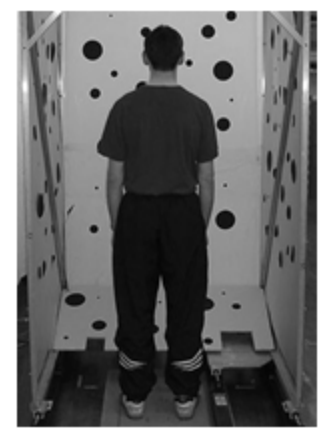

(b)

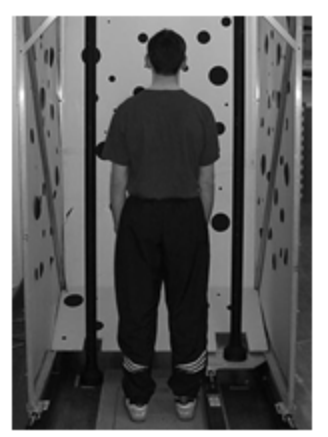

(d)

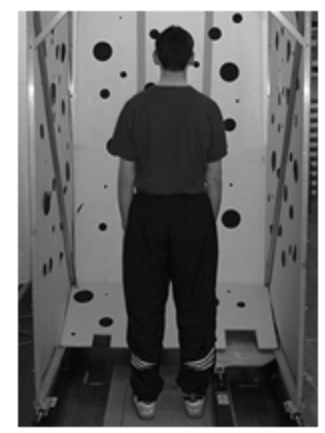

(c)

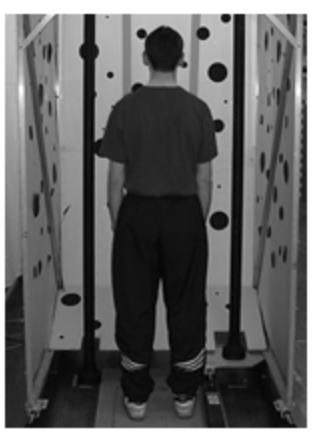

(e)

Figure 1. Experimental set-up.

\section{Experimental Protocol}

For all conditions, the subject stood on the embedded force plate and was instructed to look straight ahead. The visual surround was removed from around the force plate for the quiet standing trials and put in place for the visual surround trials. In all trials, participants

\begin{tabular}{l|l|l|l|}
\hline Torgerud et al. & 2019 & VOL.13 & N.1 \\
\hline
\end{tabular}


Brazilian Journal of Motor Behavior

were instructed to look straight ahead. Quiet standing trials (60 s duration) were conducted before and after the moving room trials (two quiet standing trials, no stationary cues in place). Five trials of each of the four moving room conditions were completed in randomized order, for a total of 20 moving room trials. At the start of the moving room trial, the room was not moving; the initial movement of the surround was away from the subject to reduce startle effects. ${ }^{9}$ Then the room translated sinusoidally at $0.24 \mathrm{~Hz}$ for $50 \mathrm{~s}$ (range $13 \mathrm{~cm}$ ). To reduce potential residual effects from the moving surround stimulus, subjects walked around the laboratory for two minutes between trials to provide true visual feedback regarding selfmotion in the environment.

\section{Data Analysis}

The COP was calculated after the forceplate data was filtered at $10 \mathrm{~Hz}$ with a fourthorder zero-phase-shift low-pass Butterworth digital filter. ${ }^{32}$ Only anterior-posterior (AP) COP was examined, as the moving room translated in the AP direction. Quiet standing trials were divided into two $25 \mathrm{~s}$ intervals $(0-25 \mathrm{~s}$ and $25-50 \mathrm{~s})$; and the moving room trials were windowed to examine the first $25 \mathrm{~s}$ after room movement. Thus, there were four $25 \mathrm{~s}$ windows of quiet standing (obtained from two $50 \mathrm{~s}$ trials), and five $25 \mathrm{~s}$ windows for each moving room condition (one window from each trial). For each time interval, COP AP root mean square (APRMS) was calculated.

The APRMS was tested for normality, and was found to be positively skewed $(p<0.01)$, as expected for COP data. The skew resulted from the floor effect - i.e. there is a minimum value. Transforming the data (squareroot $(X), \log (X)$ and $1 / X)$ improved normality, but did not provide a normal distribution $(p<0.01)$. Parametric ANOVAs assume normality, but 20 degrees of freedom for error ensures robustness of the parametric test. ${ }^{33}$ Therefore, we decided to use a parametric ANOVA. A three-way ( 2 age levels by 2 work experience levels by 5 visual conditions), repeated measures mixed model ANOVA was conducted on the APRMS (SAS 9.3, SAS Institute, Cary, NC). Significance level was set at $p \leq 0.05$.

Data were normalized two different ways, to foot length and to subject height, as these factors may influence the dependent variable. The same statistical interactions and main effects were observed with non-normalized and normalized data. This is consistent with Chiari et al. ${ }^{34}$ who found that APRMS was not influenced by height. Therefore, to facilitate understanding and comparison with existing literature, the data are reported in nonnormalized units.

\section{RESULTS}

The three-way interaction (age by work by visual condition) was not significant. The two-way interaction of work experience and visual condition was significant $(F(4,144)=2.65$, $p=0.032$, Figure 2). Post hoc analyses revealed that APRMS was not different for roofers and controls in three of the five visual stimuli conditions, but was different for the two conditions with the background references ( $18 \%$ lower for roofer with background references, and $12 \%$ lower for roofer with background and foreground references, Figure 2, asterisks). APRMS was higher for all moving room conditions when compared to quiet standing, with one exception: APRMS of the foreground and background condition for the roofer group was

\begin{tabular}{l|l|l|l|l}
\hline Torgerud et al. & 2019 & VOL.13 & N.1 & https://doi.org/10.20338/bjmb.v13i1.122
\end{tabular}


Brazilian Journal of Motor Behavior

not different from the quiet standing trial of the control group. Furthermore, for the control group in the three moving room conditions with visual cues, APRMS values were not different from the no reference condition. Conversely, roofers had lower APRMS values with foreground and background references when compared to the no reference condition.

No interactions were observed for age, but a main effect for age was observed $(F(1,144)=74.60, p<0.001)$, where young subjects demonstrated lower APRMS than middleaged subjects ( $4.2 \pm 1.6 \mathrm{~mm}$ and $4.9 \pm 1.9 \mathrm{~mm}$, respectively).

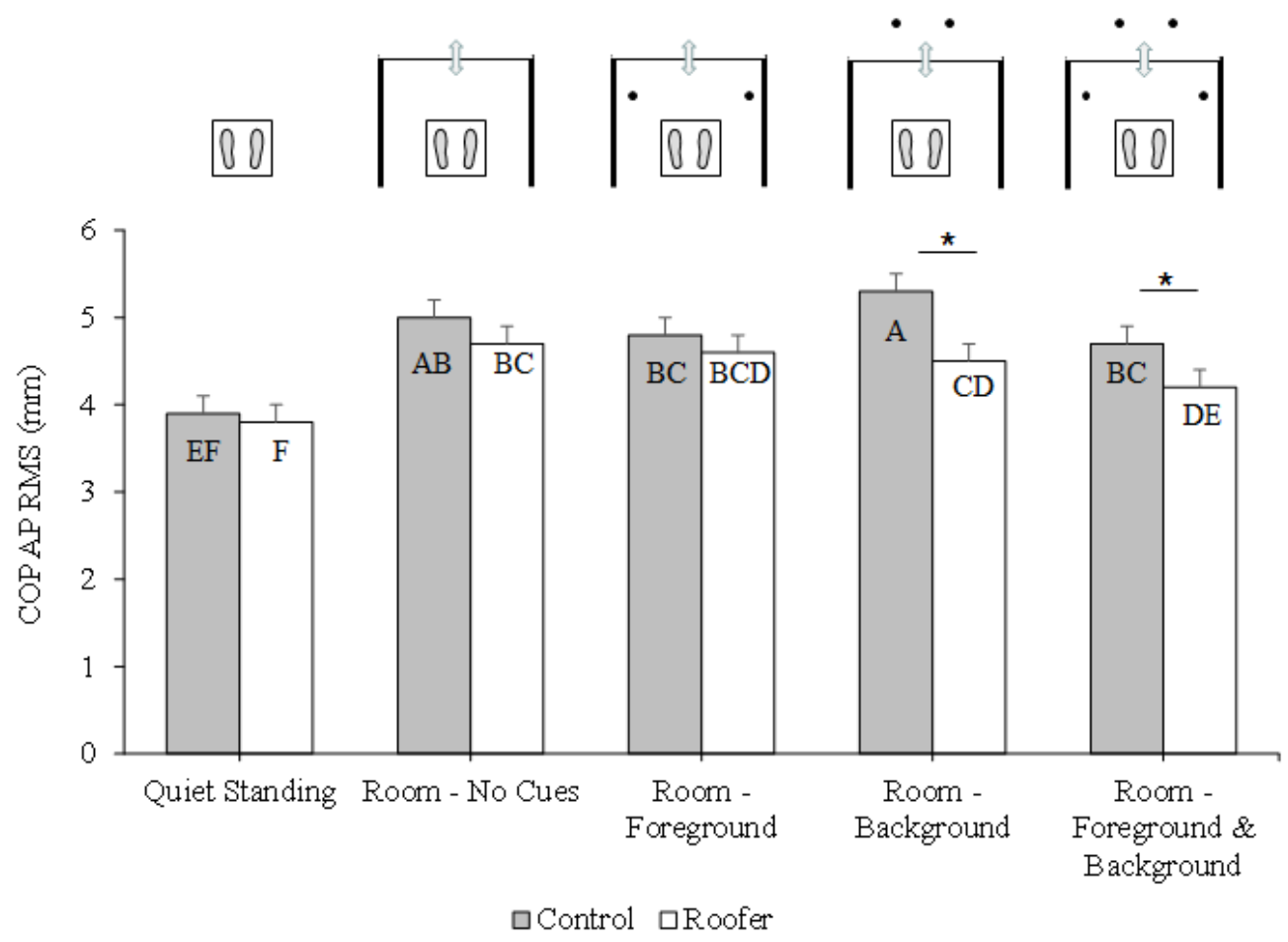

Figure 2. COP APRMS as a function of visual condition and work experience. Gray bars represent control subjects, and white bars represent roofer subjects. Error bars represent standard error. The interaction of visual condition and work experience was significant $(p=0.032)$. Differences between roofers and controls are shown with an asterisk. Different letters (A-F) identify significantly different conditions, where conditions marked $A$ are different from any other conditions which do not include an $A$. For example, $A$ is different from $B C$ but not different from $A B$.

\section{DISCUSSION}

The goal of this research was to determine how work experience in visually challenging environments affected susceptibility to the moving room stimulus, and if that susceptibility was affected by the presence of stationary visual cues. The current body of literature was extended in the following ways: (1) by examining people who had extensive experience in challenging environments at height, (2) by examining how COP APRMS was affected by static visual cues when standing inside a moving room, and (3) by examining how middle-aged roofers maintained their balance performance relative to controls. As

\begin{tabular}{l|l|l|l|}
\hline Torgerud et al. & 2019 & VOL.13 & N.1 \\
\hline
\end{tabular}

https://doi.org/10.20338/bjmb.v13i1.122 
hypothesized, people with at least two years of roofing experience were less susceptible to the moving room paradigm, but this effect was only observed when stationary cues were available in the background. These results suggest that roofers did not decrease weighting on dynamic visual information, but did increase weighting on static visual information that was visible outside a dynamic environment. COP APRMS increased with age in both work groups, but middle-aged roofers were also able to use the background cues to suppress postural sway, indicating that the ability to use static visual information was maintained despite age-related changes.

Prolonged exposure to dynamic visual environments at the worksite did not result in suppression or decreased weighting of dynamic visual information when background cues were not present (Figure 2). The lack of difference with work experience may be due the differences in magnitude, frequency, and proximity between the dynamic visual cues that a roofer experiences daily at the worksite compared to the moving room motion in the laboratory. Dynamic visual cues at the worksite include clouds and trees. Cloud motion is substantially different from the moving room: Clouds move only in one direction with varying speeds, and are not close to residential roofs. Conversely, trees will oscillate back and forth and can be within arms' length, similar to the moving room motion. Despite these similarities, the decrease in postural sway observed within one minute in the moving room in previous research ${ }^{9,10}$ did not translate to a permanent reweighting or suppression of dynamic visual stimuli for roofers. The lack of suppression of dynamic visual input likely reflects the relative importance of visual input relative to vestibular and somatosensory inputs. ${ }^{1}$ If a person were to suppress dynamic visual input, they would have less information about self-motion in the environment. For example, if a person was falling, and dynamic visual input was suppressed, it may take longer to recover balance. Therefore, even after long-term exposure to challenging environments, and perhaps especially in challenging environments, there is no evidence that dynamic visual information is suppressed following long-term exposure to dynamic environments.

However, roofers were able to use static visual information, as long as it was present in the background, in order to reduce postural sway in the moving room (Figure 2). For roofers, the APRMS decreased to such an extent with both foreground and background references that it was not different from the quiet standing condition for controls. Visual cues in the environment have been used to reduce center of pressure (COP) displacement at height and on slopes in a static lab environment, ${ }^{14,15}$ to modify locomotor behavior in young adults, ${ }^{35,36}$ and to enhance memory-guided reaching tasks. ${ }^{12}$ What is notable in the results reported here is that only the roofers were able to use stationary visual cues to reduce postural sway. Thus, extensive experience in challenging environments apparently mitigated the destabilizing effect of a dynamic visual stimulus through the use of static cues. Following the sensory weighting theory, it appears that the roofers increased weighting on the static visual information provided by stationary visual cues.

The ability to use stationary visual cues in the background was not compromised by age-related changes in middle-aged roofers. This provides support for the idea that two years of roofing experience resulted in weightings that were not modified with age and/or more experience of roofing (average number of years roofing for the young group was 6.3 years versus 17.6 for the middle-aged roofers, Table 1). Increased COP displacement in older adults due to a dynamic visual surround has been previously observed, ${ }^{11,26}$ and here 
Brazilian Journal of Motor Behavior

we demonstrate that this age-related effect is already evident at middle-age. Thus, aging roofers may be at greater risk of loss of balance, but they were able to use the stationary visual cues to stabilize themselves. This observation has relevance for the aging workforce - the limitations of inexperienced middle-aged adults in challenging worksites should be carefully considered. Furthermore, the observation that work experience may provide a protective effect may shed some light on the inconsistent findings across studies between age and occupational falls: Fall incidence has been shown to be related to age and has also been shown to have no relationship with age (see review in Chang et al., 2012). ${ }^{37}$ These inconsistencies may reflect the nature of the particular occupation included in the research; perhaps jobs that require better balance and mobility demonstrate decreased falls as a function of age and vice versa. This possibility needs to be further explored in order to fully delineate how job demands may impair or improve balance and mobility skills.

The findings of this study are limited by a number of factors. First, we have interpreted the differences as a result of sensory reweighting resulting from chronic exposure to visually dynamic environments. However, it is possible that the roofers have inherent skills or the "healthy worker survivor effect" (e.g. Brown et al., 2017) ${ }^{38}$ may explain the observed differences. For roofers, a misstep or momentary loss of balance could lead to severe injuries or death. Roofing employers reported to us that the drop-out rate is greater for roofers than other construction industries. Therefore, workers without adequate balance strategies may have removed themselves from the roofing industry, either by quitting or suffering a fall-related injury which excluded them from the industry. A longitudinal study is needed to assess whether the postural strategies/weightings are learned through work experience or if they result from inherent skills. Note that inherent skills may also include the ability to quickly develop balance skills, or to quickly adjust weightings based on sensory conflict. Another potential limitation is that roofers may be stronger than controls, or had different amounts of attention in the balance task, which may lead to lower APRMS. This concern is mitigated by the within-subject component of the study design: if decreased COP RMS was a consequence of a constant factor such as strength, the decrease would be the same regardless of location of stationary cues. The older groups weighed more than the younger groups, and the control groups weighed more than the roofer groups (Table 1), which may have affected the behavior. However, as above, the within-subject component of the study design mitigates this concern: if higher COP RMS was a consequence of weight, the differences would have been observed across all conditions. Finally, the placement of the visual references must be considered. They were placed in the foreground and background to be consistent with the vection literature (e.g. Howard and Howard, 1994). ${ }^{16}$ However, the background references were placed in the central visual field, and the foreground references were more peripheral (Figure 1). Therefore, the differences described in this paper as a function of foreground versus background could result from peripheral versus central placement (or a combination of both). However, this would not change the inherent argument of this paper - that stationary cues were used differently by the roofers versus controls.

In order to more fully understand the role of chronic exposure to challenging worksites, future research should continue to quantify measures of gait and balance across multiple industries. For example, construction workers have higher balance demands at work, and demonstrated better scores on a functional balance test than fire fighters, and 
Brazilian Journal of Motor Behavior

both of these groups demonstrated better scores than nursing staff and homecare workers. ${ }^{30}$ Longitudinal studies of workers transitioning from low-challenge to high-challenge worksites - and vice versa - will reveal new insights regarding the role of the environment in balance adaptations. While working in challenging environments increases fall risk, ${ }^{20}$ this environment may mitigate deconditioning associated with aging.

\section{CONCLUSION}

Roofers were as susceptible to dynamic visual information as controls when background cues were not available. However, roofers do appear to have greater weighting on static visual information, which, when available, allows them to suppress dynamic visual information. Furthermore, this weighting is evident in both young and middle-aged roofers, indicating that this ability is resistant to age-related changes, at least in those who remain in the roofing industry.

\section{REFERENCES}

1. Horak FB, Macpherson JM. Postural orientation and equilibrium. Handbook of physiology. 1996;1:255-292.

2. Johansson R, Magnusson M, Fransson PA. Galvanic vestibular stimulation for analysis of postural adaptation and stability. IEEE Transactions on Biomedical Engineering. 1995;42(3):282-292.

3. Peterka R. Sensorimotor integration in human postural control. Journal of neurophysiology. 2002;88(3):1097-1118.

4. Fransson P, Hafström A, Karlberg M, Magnusson M, Tjäder A. Postural control adaptation during galvanic vestibular and vibratory proprioceptive stimulation. IEEE Transactions on Biomedical Engineering. 2003;5(12):1310-1319.

5. Fransson PA, Johansson R, Hafström A, Magnusson M. Methods for evaluation of postural control adaptation. Gait \& posture. 2000;12(1):14-24.

6. Fransson PA, Magnusson M, Johansson R. Analysis of adaptation in anteroposterior dynamics of human postural control. Gait \& posture. 1998;7(1):64-74.

7. Fransson PA, Tjernström F, Hafström A, Magnusson M, Johansson R. Analysis of shortand long-term effects of adaptation in human postural control. Biological cybernetics. 2002;86(5):355-365.

8. Tjernström F, Fransson P, Hafström A, Magnusson M. Adaptation of postural control to perturbations-a process that initiates long-term motor memory. Gait \& posture. 2002;15(1):75-82.

9. Loughlin PJ, Redfem MS, Furman JM. Time-varying characteristics of visually induced postural sway. IEEE transactions on rehabilitation engineering. 1996;4(4):416-424.

\begin{tabular}{l|l|l|l|}
\hline Torgerud et al. & 2019 & VOL.13 & N.1 \\
\hline
\end{tabular}


10. Loughlin PJ, Redfern MS. Spectral characteristics of visually induced postural sway in healthy elderly and healthy young subjects. IEEE Transactions on neural systems and rehabilitation engineering. 2001;9(1):24-30.

11. Haibach $P$, Slobounov S, Newell K. Egomotion and vection in young and elderly adults. Gerontology. 2009;55(6):637-643.

12. Krigolson $\mathrm{O}$, Heath M. Background visual cues and memory-guided reaching. Human movement science. 2004;23(6):861-877.

13. Rietdyk S, Drifmeyer JE. The rough-terrain poblem: accurate foot targeting as a function of visual information regarding target location. . Journal of motor behavior. 2010;42(1):37-48.

14. Simeonov $\mathrm{P}, \mathrm{Hsiao} \mathrm{H}$. Height, surface firmness, and visual reference effects on balance control. Injury Prevention. 2001;7(Suppl I):50-53.

15. Simeonov PI, Hsiao H, Dotson BW, Ammons DE. Control and perception of balance at elevated and sloped surfaces. Human Factors. 2003;45(1):136-147.

16. Howard IP, Howard A. Vection: the contributions of absolute and relative visual motion. Perception. 1994;23(7):745-751.

17. Nakamura S, Shimojo S. Critical role of foreground stimuli in perceiving visually induced self-motion (vection). Perception. 1999;28(7):893-902.

18. Prothero JD, Draper MH, Parker DE, Wells MJ. The use of an independent visual background to reduce simulator side-effects. Aviation, space, and environmental medicine. 1999;70(3 Pt 1):277-283.

19. Previc FH. The effects of dynamic visual stimulation on perception and motor control. J Vestib Res. 1992;2(4):285-295.

20. Scott KA, Fisher GG, Barón AE, Tompa E, Stallones L, DiGuiseppi C. Same-level fall injuries in US workplaces by age group, gender, and industry. American journal of industrial medicine. 2018;61(2):111-119.

21. Nigam Y, Knight J, Bhattacharya S, Bayer A. Physiological Changes Associated with Aging and Immobility. Journal of aging research. 2012;2012:2 pages.

22. Hollman JH, Kovash FM, Kubik JJ, Linbo RA. Age-related differences in spatiotemporal markers of gait stability during dual task walking. Gait \& posture. 2007;26(1):113-119.

23. Auvinet B, Berrut G, Touzard C, et al. Reference data for normal subjects obtained with an accelerometric device. Gait \& posture. 2002;16(2):124-134.

24. Muir BC, Haddad JM, van Emmerik REA, Rietdyk S. Changes in the control of adaptive gait in middle age become evident as gait task difficulty increases. In press. Gait and Posture.

25. Van Emmerik REA, McDermott WJ, Haddad JM, Van Wegen EE. Age-related changes in upper body adaptation to walking speed in human locomotion. Gait \& Posture. 2005;22(3):233-239.

26. Woollacott MH. Systems contributing to balance disorders in older adults. The Journals of Gerontology Series A. 2000;55(8):M424-428. 
Brazilian Journal of Motor Behavior

\section{Research Article}

27. Stevens J, Sogolow E. Preventing Falls: What Works. A CDC Compendium of Effective Community-Based Interventions from Around the World. Atlanta, GA: Centers for Disease Control and Prevention, National Center for Injury Prevention and Control; 2008.

28. Wegman DH, McGee JP. Health and Safety Needs of Older Workers/Committee on the Health and Safety Needs of Older Workers. Washington, DC: The National Academies Press; 2004.

29. Gall B, Parkhouse W. Changes in physical capacity as a function of age in heavy manual work. Ergonomics. 2004;47(6):671-687.

30. Punakallio A. Balance abilities of different-aged workers in physically demanding jobs. Journal of occupational rehabilitation. 2003;13(1):33-43.

31. Rietdyk S, Mcglothlin JD, Knezovich MJ. Work experience mitigated age-related differences in balance and mobility during surface accommodation. Clinical biomechanics. 2005;20(10):1085-1093.

32. Winter DA. Biomechanics and Motor Control of Human Movement. 2nd Ed. New York: Wiley; 1990.

33. Tabachnick BG, Fidell LS. Using Multivariate Statistics. Northridge. Cal: Harper Collins; 1996.

34. Chiari L, Rocchi L, Cappello A. Stabilometric parameters are affected by anthropometry and foot placement. Clinical biomechanics. 2002;17(9-10):666-677.

\section{ACKNOWLEDGEMENTS}

We would like to acknowledge the participants for their time and willingness to participate, and Mr. Paul O'Dell for allowing us to interact with his employees and to observe the roofers at the worksite.

\footnotetext{
Citation: Torgerud SR, Cho H, McGlothlin JD, Rietdyk S.Work experience at height suppressed the effect of dynamic visual input on postural sway when static visual cues were visible. BJMB. 2019: 13(1): 11-22.

Editor: Dr Fabio Augusto Barbieri - São Paulo State University (UNESP), Bauru, SP, Brazil; Dr José Angelo Barela - São Paulo State University (UNESP), Rio Claro, SP, Brazil; Dr Natalia Madalena Rinaldi - Federal University of Espírito Santo (UFES), Vitória, ES, Brazil.

Copyright: ( 2019 Torgerud, Cho, McGlothlin and Rietdyk and BJMB. This is an open-access article distributed under the terms of the Creative Commons Attribution-NonCommercial-NoDerivatives 4.0 International License which permits unrestricted use, distribution, and reproduction in any medium, provided the original author and source are credited.

Funding: This research was supported by the National Institute for Occupational Safety and Health through the University of Michigan Center for Occupational Health and Safety Engineering.

Competing interests: The authors have declared that no competing interests exist.

DOl:https://doi.org/10.20338/bjmb.v13i1.122
}

\begin{tabular}{l|l|l|l|}
\hline Torgerud et al. & 2019 & VOL.13 & N.1 \\
\hline
\end{tabular}

